\section{В.Г. КУДРЯВЦЕВ}

Марийский государственный университет

г. Йошкар-Ола, Россия

ORCID: 0000-0002-1421-1664

vladku2004@mail.ru

\section{VLADIMIR G. KUDRYAVTSEV}

Mari State University

Yoshkar-Ola, Russia

ORCID: 0000-0002-1421-1664

vladku2004@mail.ru

\section{Семантическая система народного марийского костюма \\ и его художественно- образная интерпретация*}

Статья посвящена изучению традиционного марийского костюма, объединяющего мировоззренческие, эстетические и художественные представления об окружающем мире. Семантическая система народного костюма и его художественно-образная интерпретация предполагает единство их утилитарного и декоративного предназначения. На основе изучения археологического, этнографического и искусствоведческого материала выявляются этноопределяющие истоки, важные для развития практики современного этнодизайна.

\section{Ключевые слова:}

марийская традиционная культура, этнодизайн, народный костюм, художественная и семантическая система.

\section{The Semantic System of the Mari Folk Costume and its Artistic-Figurative Interpretation**}

The article is devoted to the study of the traditional Mari costume, which unifies the worldview, aesthetical and artistic perceptions of the surrounding world. The semantic system of the folk costume and its artistic-figurative interpretation presumes a unity of their utilitarian and decorative purposes. On the basis of studies of material related to archeology, ethnography and art studies the ethnic-determining sources are revealed which are important for the development of the practice of contemporary ethnic design.

\section{Keywords:}

traditional Mari culture, ethnic design, the folk costume, artistic and semantic system.

Для иитирования/For citation:

Кудрявцев В.Г. Семантическая система народного марийского костюма и его художественно-образная интерпретация // ИКОНИ / ICONI. 2020. № 3. С. 68-79. DOI: 10.33779/2658-4824.2020.3.068-079.

\footnotetext{
* Публикация подготовлена в рамках поддержанного РФФИ научного проекта № 17-34-00006-ОГН.

** The publication is prepared as part of scholarly project No. 17-34-00006-OGN with the support of the Russian Fund of Fundamental Research.
} 
$\mathrm{H}$ ародное искусство с его богатейшими традициями как форма этнического самосознания занимает особое место в художественном наследии, изучение которого от археологических и этнографических истоков становится особо важным в современном этнодизайне.

Семантическая система традиционного марийского народного костюма и его художественно-образная интерпретация соединяют воедино мировоззренческие, эстетические и художественные представления народа, проявляясь как в утилитарном, так и в декоративном предназначении [10, с. 7]. Современные исследователи провозглашают тезис,

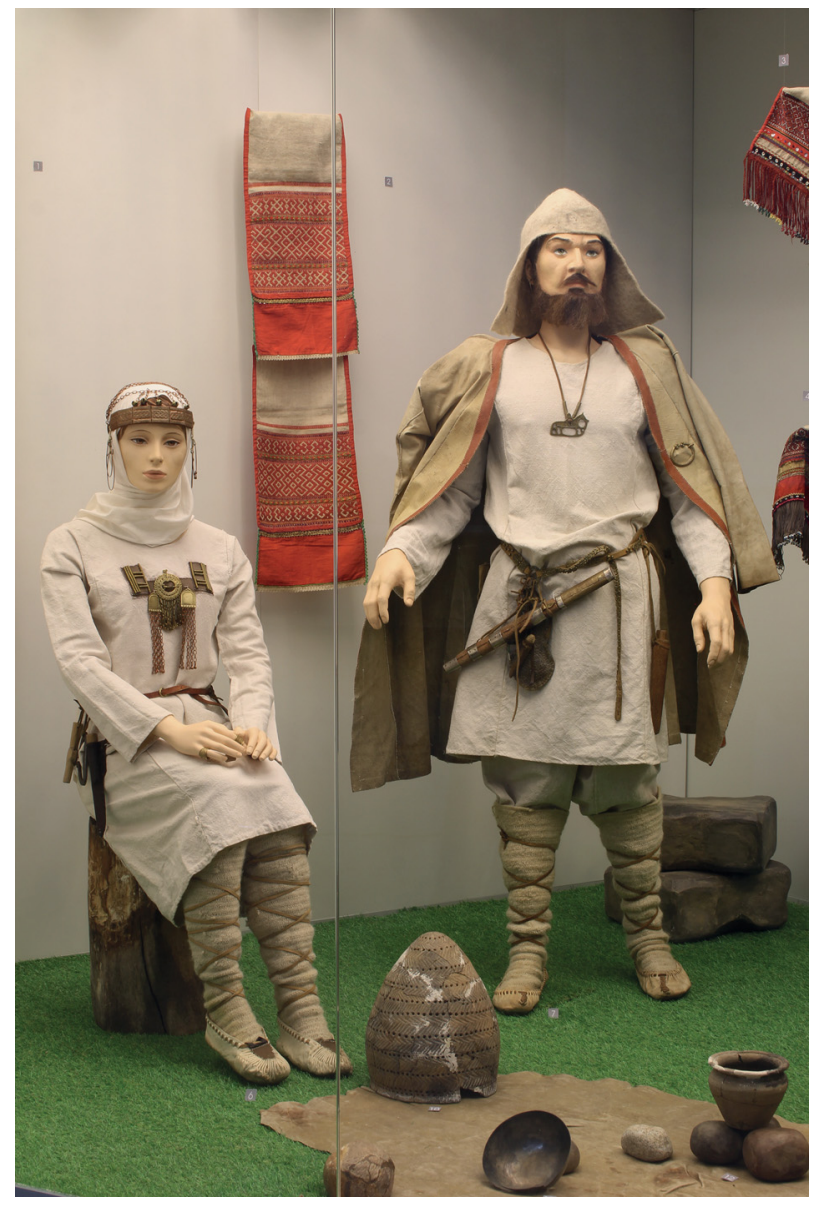

Фото 1. Древнемарийский костюм.

Реконструкция.

Национальный музей

Республики Марий Эл

Им. Т.Е. Евсеева

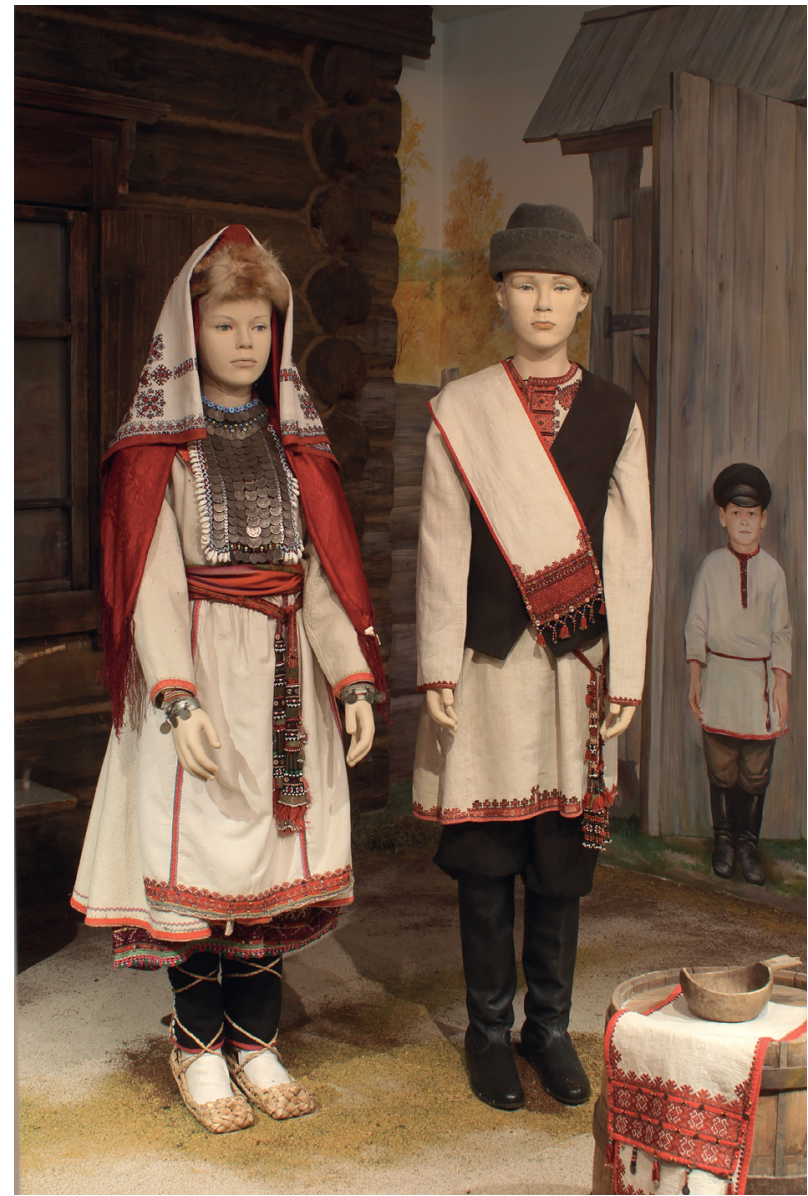

Фото 2. Свадебный костюм луговых мари.

Конеи XIX - начало XX века.

Из фондов Национального музея

Республики Марий Эл

Им. Т.Е. Евсеева

что изобразительные методы самовыражения традиционных культур, их абстрагированное или знаковое изображение мира неизменны [4, с. 4].

Эволюция традиционного костюма позволяет проследить не только трансформацию народных представлений и художественных идеалов, но и глубокие изменения в общественном, семейном быте, особенности развития народного хозяйства на том или ином этапе, миграционные потоки. Возникновение стиля одежды и украшений представляет собой творческий акт, имеющий внутренний закономерный смысл; а в ходе исторического развития на него накладываются 
затушёвывающие первоначальный смысл напластования или хранящие рудименты культурные традиции [2, с. 76].

Марийский народный костюм оформился в древности и изменялся на протяжении многих веков. Архаическую картину мира отражают некоторые традиционные семантические элементы, бытующие в обрядовом костюме (свадебном, погребальном, молельном) [11, c. 124]. По археологическим изысканиям сделана реконструкция древнемарийского костюма [1, с. 20]. Средневековый женский костюм состоял из холщовой рубашки туникообразного покроя с поясом, летнего и зимнего кафтана, штанов, головного убора, кожаной обуви и украшений, а зимняя одежда включала кафтан из телячьей кожи (мехом внутрь) и меховые рукавицы. Важную роль играли выполняемые из серебра и меди украшения. Женщины носили головной убор или налобные венчики из ткани с нашитыми бронзовыми бусинками, цепочками, использовали бронзовые и серебряные височные кольца. Шейные украшения составляли гривны, бусы или ожерелья. В нагрудной части на одежду нашивались подвески-амулеты. Они представляли собой фигурки птиц, коней. Украшениями рук были браслеты и перстни. Таким образом, в металлопластике сложились основные информационные коды, которые впоследствии транслировались в искусство вышивки и сохранили древние идеограммы. Археологический материал подтверждает, что в эпоху раннего средневековья для древнемарийских племён была характерна вышивка медной проволокой [9, с. 13-14, 16].

К X-XI векам относится расцвет самобытной древнемарийской культуры. В широком ассортименте местных художественных изделий из меди, бронзы, серебра (в очень редких случаях - золота) свободно варьируются и сочетаются технические приёмы и декоративные особенности литья, чеканки, насечки, гравировки, основу которых составляет

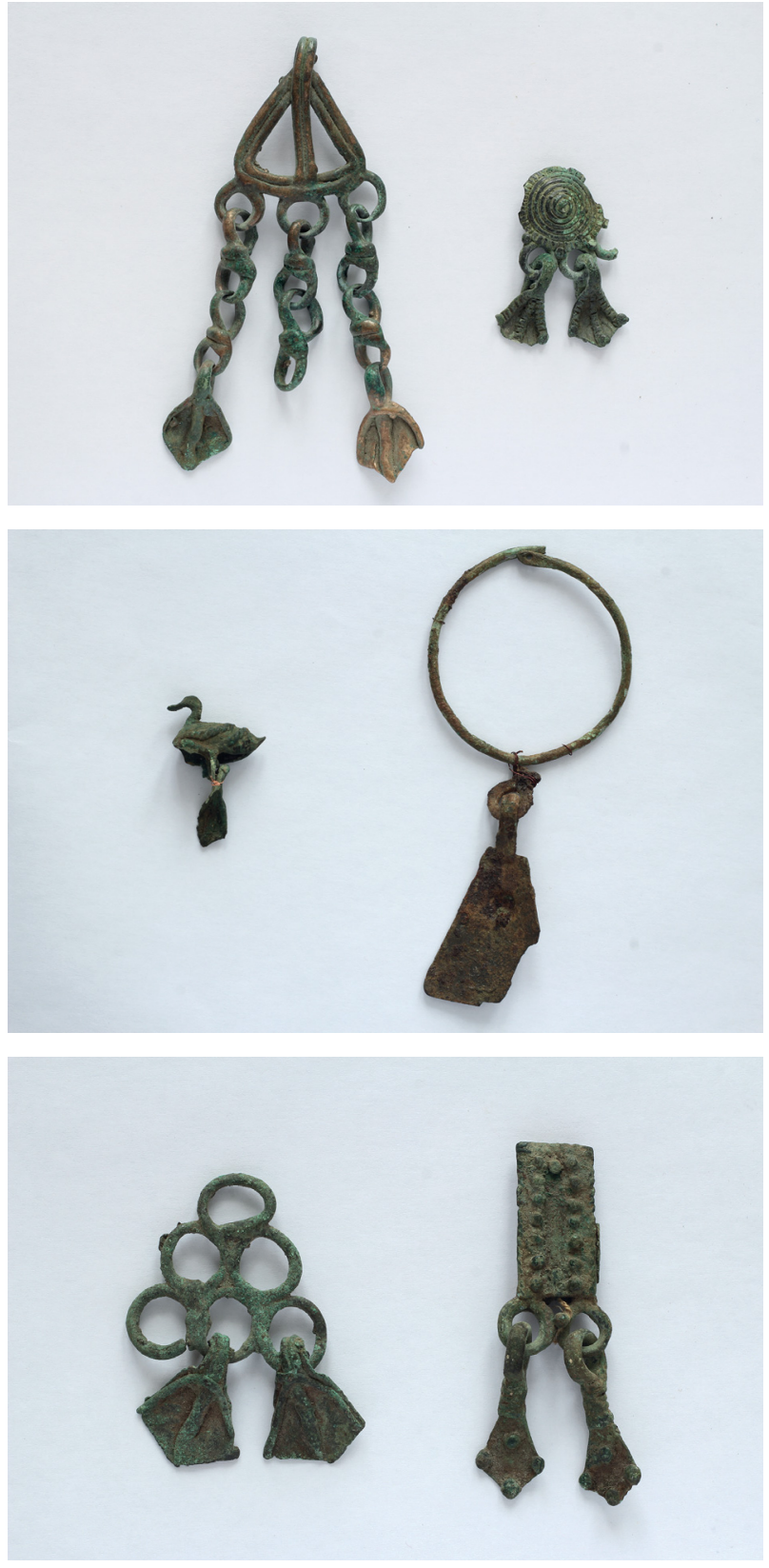

Фото 3. (a, b, c). Древнемарийские украшения. Национальный музей Республики Марий Эл Им. T.Е. Евсеева

выразительная графика, чёткий рисунок. Основными женскими украшениями головы у марийцев в IX-XI веках были венчики, а также свойственные только им медные цепочки, которых нет у других финно-угорских народов; в нагрудной части встречаются шумящие подвески с основой-щитком трапециевидной формы. 
В искусстве финно-угорских народов изображение водоплавающей утки один из основных мотивов. Эволюция этого образа от обобщённой полой фигурки с двумя кольцами для крепления подвесок в форме утиных лапок развивается к подробно разработанным крыльям и другим элементам декоративных изображений фигурок. Эти полые литые подвески-уточки с ободком по краю и отверстием для привешивания являлись характерным этническим признаком древних марийцев [3, с. 17, 19]. Фигурки уточек использовались в ансамбле женского костюма в качестве нагрудного украшения и подвесок к поясу и косам, служили оберегом и были связаны с идеей плодородия. Культ этой птицы, жертвуемой в языческих молениях в священной роще, сохранился до настоящего времени.

Изобразительные мотивы, включающие разнообразные зооморфные (кони, медведи, птицы) и антропоморфные сюжеты (подвески на ожерельях в виде миниатюрных фигурок всадниц на конях из серебра), были подчинены строгой ритмической организации всей целостной композиции. Распространённым типом были коньковидные нагрудные украшения - трапециевидные пластины, в верхней части которых располагались парные стилизованные изображения коней с симметрично развёрнутыми в разные стороны мордами. Такие подвески попарно нашивались на кожаные нагрудники. Как отмечал Г.А. Архипов, "сохранившиеся остатки высококачественных изделий из кожи (одежда, обувь, кошельки, сумки, ножны, перчатки, другие вещи) свидетельствуют о том, что некоторые изделия... не уступали новгородским изделиям X-XI вв.» [1, с. 20].

Организующим центром костюмного комплекса считался кожаный ремень-пояс, декорированный металлическими накладками. Мужчины к поясу крепили колчан со стрелами, ножны с кинжалом, мечом или саблей, кошелёк с необходи- мыми принадлежностями, а женщины дополняли его шумящими привесками, зооморфными гребнями, изящными серебряными ножнами. В целом искусство металлопластики охватывало и пронизывало всю систему материальной и духовной культуры.

Для изготовления одежды использовалась домотканина из конопли, льна и шерсти, также применялось и крапивное волокно. Вплоть до начала XX века народный костюм изготавливался преимущественно домашним способом с использованием самодельных тканей. Меховые кафтаны сшивались из шкур выделанной в домашних условиях овчины, а для их отделки использовался мех диких зверей. В женском костюме дольше сохранялись самобытные черты. Локальные отличия выявляются в покрое нижней части рубахи и рукавов, в расположении грудного разреза, а также в композиционном размещении орнамента. Немаловажное значение для выделения вариантов женской рубахи имеет расположение грудного разреза на правой стороне и в центре. По всей вероятности, грудной разрез в центре основной точи холста стали размещать со второй половины XIX века. Отдельные составные части костюма, тип отделки, украшения позволяют различать костюм трёх основных этнографических групп мари - луговых, горных и восточных. Женская же рубаха у всех этнографических групп была однотипной [8, с. 54-63].

Народный костюм богато оформлялся вышивкой. Старинная вышивка была плотной и чётко очерченной. Основные мотивы в орнаменте - изображения комбинаций различных геометрических, растительных, зооморфных, антропоморфных фигур. В древности вышивка выполняла магическую функцию, указывала на принадлежность её владельца к определённой этнической группе, роду. Наиболее богатой орнаментацией отличалась женская рубаха Царёвококшайского уезда Казанской губернии, 
на которой вышивка располагалась как на груди, на концах рукавов и подоле, так и вдоль всего рукава, на уровне груди, на спине. Орнамент дополнял также продольные швы рубахи. Для её оформления марийки использовали крашеную шерстяную пряжу. В Уржумском уезде Вятской губернии в первой четверти XIX века вместо шерсти использовали шёлк-сырец, окрашенный в домашних условиях [6, с. 62-64]. Отделка рубах лентами, тесьмой, пуговицами, бисером, как и расположение вышивки, определялась давними традициями. У горных мари рубаха в конце XIX века имела скудную орнаментацию. Изменение её характера объясняется вытеснением конопляного холста тонкой домотканиной из фабричных ниток: вышивка стала более мелкой.

Женская рубаха восточных мари имела свою особенную эволюцию. Этнограф Г.А. Сепеев выделил два этапа развития костюма, который из белого холщового превратился в пестрядинный. Рубаха туникообразного покроя стала иметь широкий подол, напоминала башкирскую и татарскую, вышивка заменилась тканым узором, оборками, лентами [12, с. 89-91]. Конструктивно крой представлял перекинутый со спины на грудь кусок холста, составлявший стан. В нём вырезалась горловина для ворота. К этой центральной точе по прямой нитке пришивались невырезные рукава с ластовицами треугольной или квадратной формы. С боков под рукавами, захватывая их, помещались боковины. Для всех женщин мари было характерно ношение штанов.

Верхняя одежда состояла из кафтана: летний был из холста, осенне-весенний — из сукна, зимний — из утеплённого сукна, также в ходу были шубы из овчины чёрного или коричневого цветов.

Существенным образом дополняли народный костюм пояса, передники и поясные украшения. Пояса подразделялись на два вида: повседневные и праздничные. Будничные пояса длиной до 2-2,5 метров и шириной 2-4 сантиметра ткали из разноцветной шерстяной, реже шёлковой пряжи. К таким поясам привешивались мешочки для хранения денег, иголок, ниток и т. д. Празднично-обрядовые пояса украшались монетами, кистями, бусами, пуговицами, поэтому за ними закрепилось название «пояс с серебром». Для опоясывания верхней одежды применялись самотканые шерстяные кушаки из шерстяных и конопляных ниток (длина кушака достигала 3 метров, ширина 10-15 сантиметров). Поверх рубахи женщины и мужчины носили кафтан.

Важной частью костюма являлся передник. Бытовало два его подтипа: без грудки и с грудкой. Передник без грудки был двух видов: один состоял из одной точи холста и украшался вышивкой, тесьмой, кружевом (бытовал у луговых мари Царёвококшайского уезда), второй — из одной точи холста с двумя пришитыми боковыми половинками, украшенными вышивкой из шёлковых ниток (Уржумский уезд). Передник с грудкой вошёл в состав костюмного комплекса горных и восточных мари в конце XIX века. У восточных мари фартук украшался тканым узором, лентами, позументом, бисером, блёстками [12, с. 108].

Важным элементом народного костюма являются головные украшения. Головной убор подтверждал этническую принадлежность носительницы, её возраст и общественное положение, имел апотропейную (защитную) функцию. Налобная повязка, обшитая кожей, имела берестяную основу и завязывалась сзади. Сверху нашивались или заклёпывались накладки четырёхугольной формы с повторяющимся одинаковым орнаментом. Над налобной повязкой прикреплялась медная цепочка в 2 оборота, от которой сзади опускались медные полые шарики. За ушами от налобной повязки на кожаных шнурках с нанизанными спиральками или другими предметами привешивались подвески (коготки рыси). В височной части размещались парные кольца. Налобная повязка с течением 


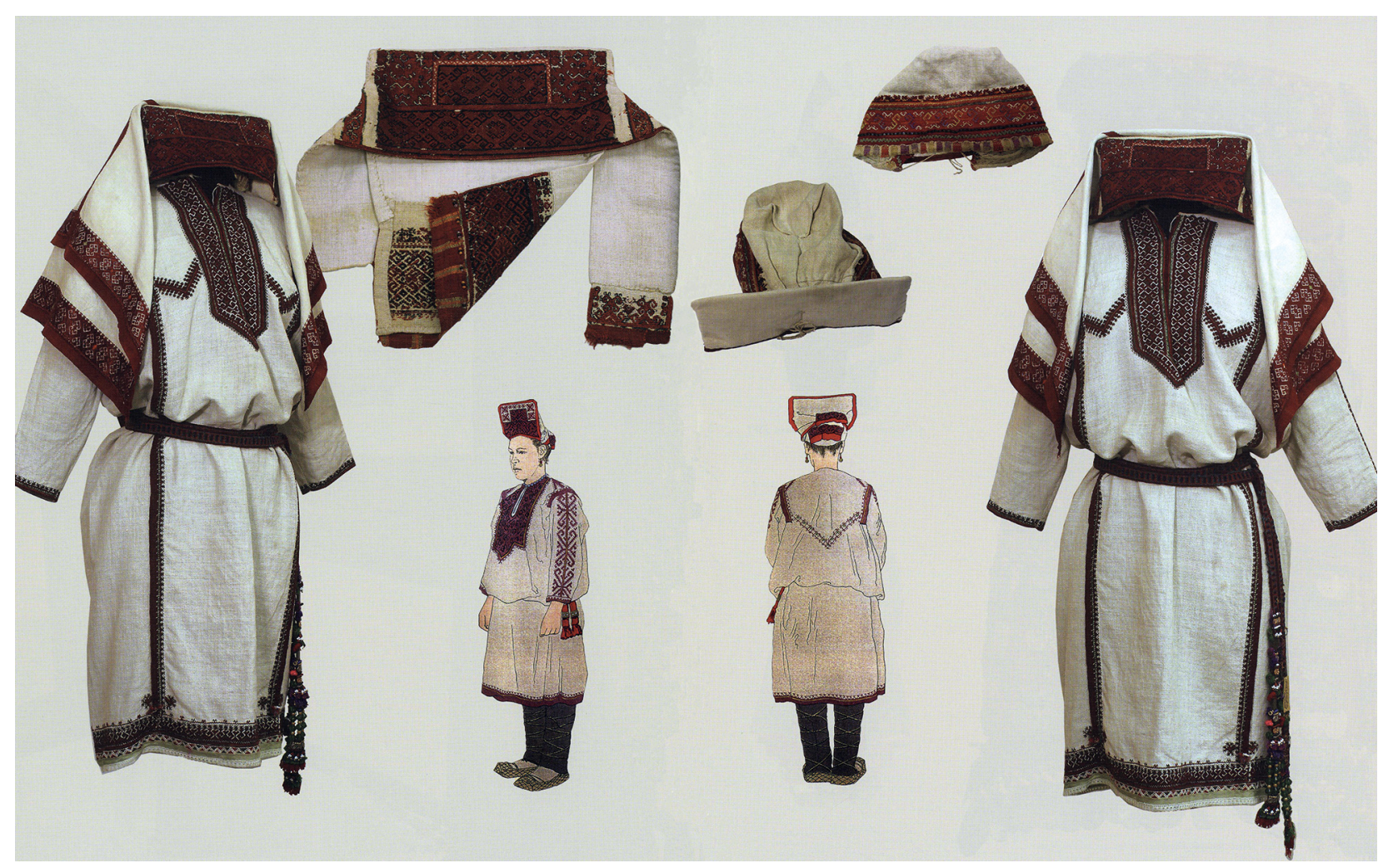

Фото 4. Костюм луговой марийки с головным убором сорока. Конец ХІХ - начало ХХ века.

Из фондов Национального музея Республики Марий Эл им. Т.Е. Евсеева

времени приняла форму головного убора соро́ка. Этот каркасный головной убор состоял из очелья на твёрдой прямоугольной основе из берёсты или кожи. С боков к очелью пришивались завязки. Сороку изготовливали из тонкого льняного холста и богато заполняли вышивкой [5, с. 302]. Головной убор надевался на холщовую шапочку-волосник.

Другой старинный головной убор шурка́ - имел берестяную или кожаную основу в форме усечённого конуса высотой 30-40 сантиметров и шириной в верхней части 10 сантиметров. Этот берестяной остов обтягивали тканью красного цвета, оформляли вышивкой, на которую рядами нашивались бусы, монеты, бисер. В центре находилась серебряная или бронзовая подвеска.

Костюм девушки отличался от костюма замужней женщины. Основным головным убором девушек был платок.
А замужние женщины носили каркасные остроконечные шурка, сорока, шымакш, шарпан. Ношение головного убора символизировало социальный статус женщины. Если девушка могла ходить с открытыми волосами, то покрытие головы замужних женщин являлось неписаным законом, несоблюдение которого влекло за собой наказание. А во время свадебного обряда происходила смена девичьего головного убора на головной убор замужней женщины.

Шурка заменяется более лёгким и удобным убором шыма́кш. Он имеет конусообразную форму, которая как формообразующий элемент стала характерной в народном искусстве и зодчестве мари (например, традиционная зерносушилка овин-шиш, берестяной головной убор жреца). Шымакш представляет собой прямоугольный кусок холста размером 55×20 сантиметров, один конец которого 


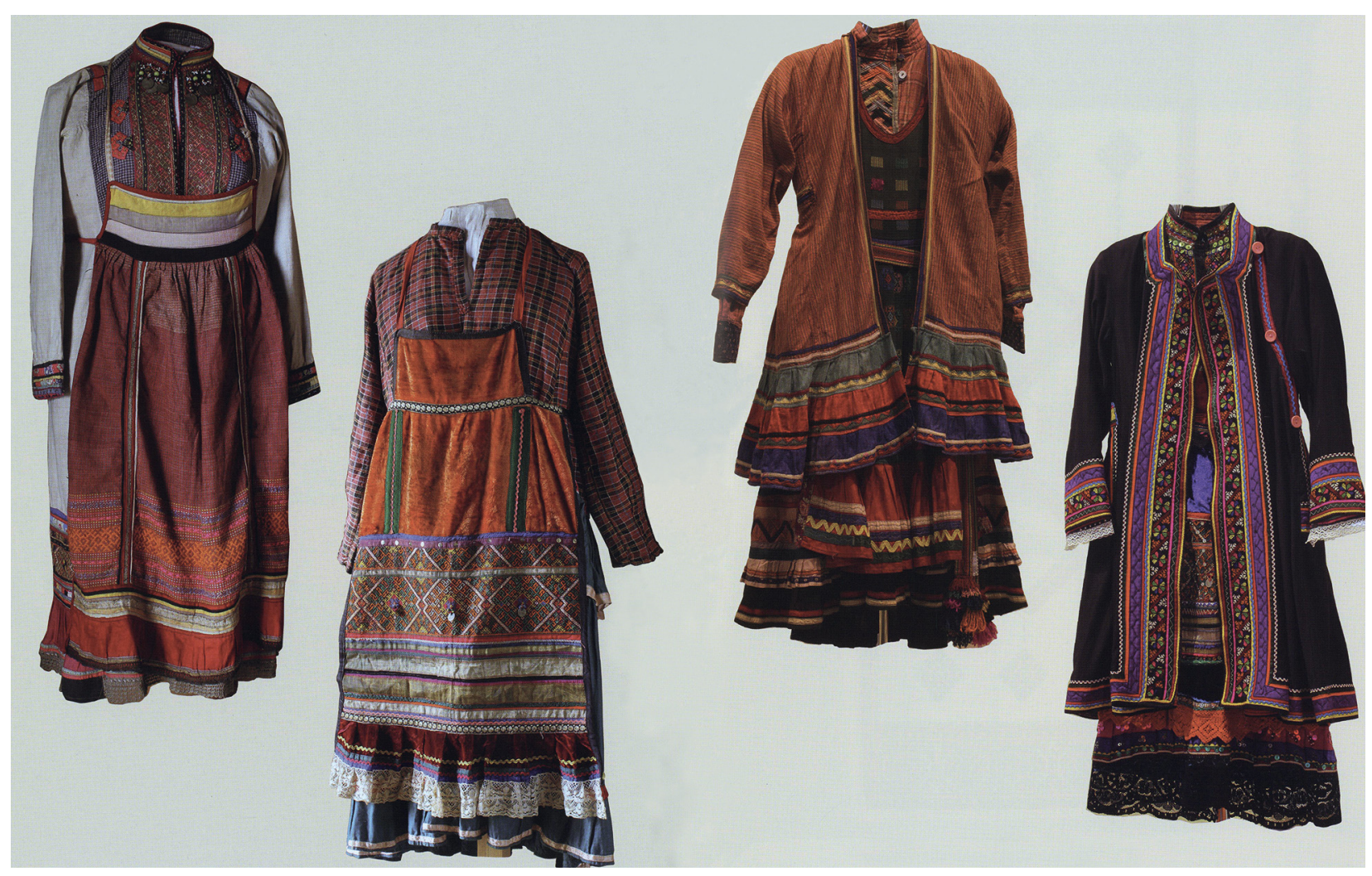

Фото 5. Женский костюм восточных мари. Конец XIX - начало XX века.

Из фондов Национального музея Республики Марий Эл им. Т.Е. Евсеева

сшивался в виде колпачка. Надевался на твёрдую основу - берестяной рожок или туго свитый пучок волос. Шымакш сплошь вышивался, причём орнамент был строго определённым. Конец головного убора украшали бисером, мелкими пуговицами, кисточками, бахромой, иногда монетами [5, с. 328]. Поверх него надевался холщовый треугольный платок. Шымакш был распространён среди луговых и восточных мари. Манера его надевания различна: луговые мари надевали острием конуса вверх, а восточные - вперёд, из-за чего он напоминал клюв птицы.

В наиболее ранних образцах орнамент сорока состоял из животных мотивов, в более поздних приобретал геометрические очертания. Богато декорированный вышивкой и тесьмой полотенчатый шарпа́н из холста носили с вышитым начелышем нашма́к - узкой орнаментиро- ванной полоской холста, прикрепляемой с помощью металлических заколок. Изображения коня, птицы, иногда собаки, человека у Древа жизни были преобладающими в этом типе головного убора, что отразилось и в терминологии орнаментов. В более поздних образцах нашмака и сороки получили распространение геометрические узоры - звёзды, квадраты, зигзагообразные линии, ромбы и прочие.

У горных мари шарпан имел песочный цвет, концы оформлялись вышивкой, лентами, бисером, позументом, кружевом. Узор вышивки состоял из поперечных полос, в каждой содержались определённые изображения-символы. Искусно выполняемые женщинами узоры-символы на шарпане, словно книга, повествовали о жизни и мечтах вышивальщицы. Если они были заимствованы, то к ним пришивалась шёлковая лента или кисточка. 


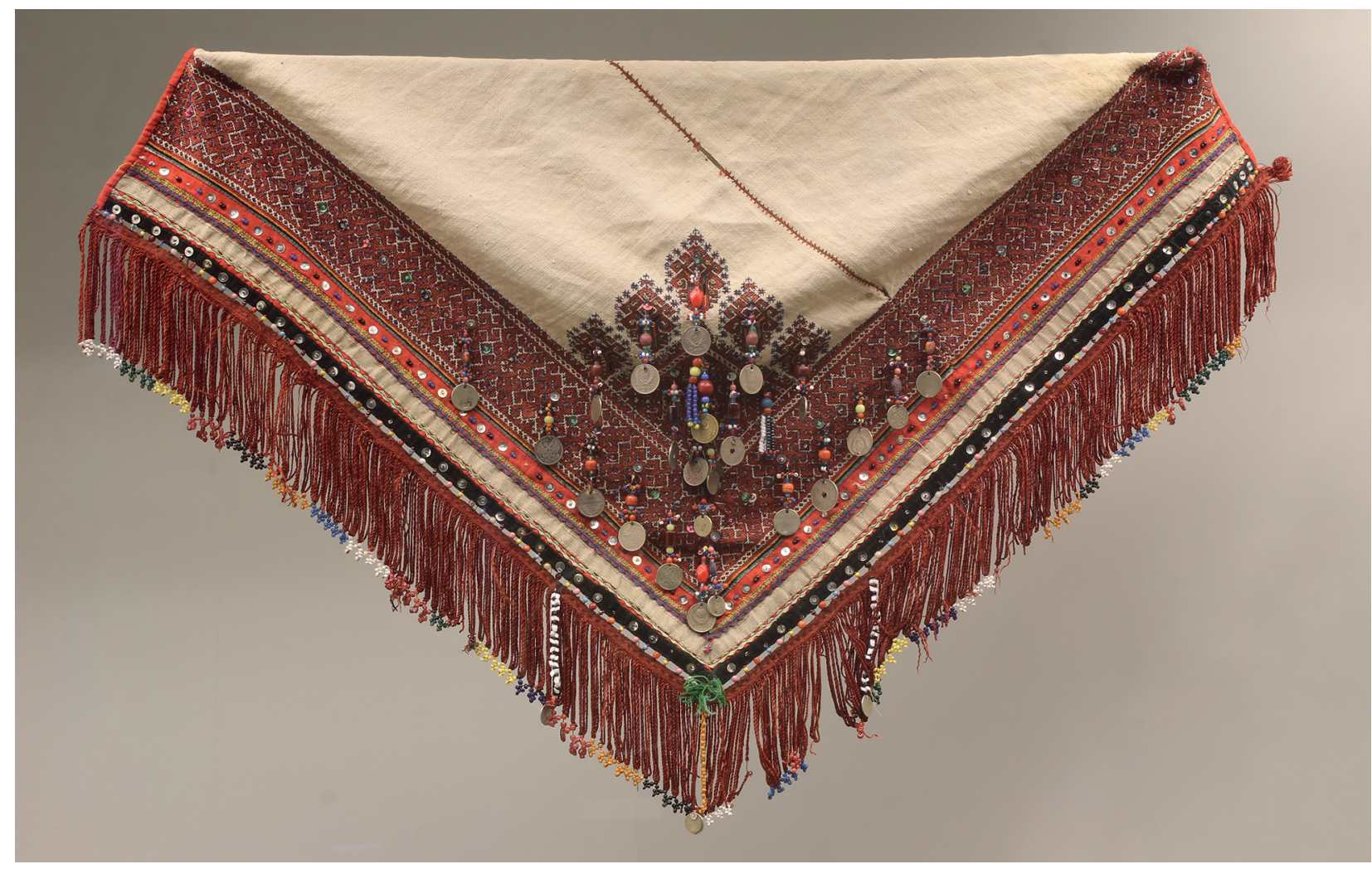

Фото 6. Свадебный платок.

Конец XIX - начало ХХ века.

Из фондов Национального музея Республики Марий Эл им. Т.Е. Евсеева

Шарпан у горных мари, по мнению исследователей, выступал не как головной убор, а как наспинное украшение [5, c. 254]. У луговых мари шарпан был короче, чем у горных, и не превышал двух метров.

Платки из холста с вышивкой носили поверх остроконечного шымакша и сороки. Они были треугольной и квадратной формы, последние надевались таким образом, чтобы были видны вышитые розетки.

Мужской костюмный комплекс состоял из головного убора, рубахи, штанов, кафтана, пояса и обуви. Нательной и верхней одеждой была рубаха, сшитая из сложенного пополам основного полотнища и двух боковых. Рукава пришивались по прямой линии. К концу XIX века подобный тип мужской рубахи был вытеснен рубахами-косоворотками. Рубашку мужчины носили подпоясанной. В ста- ринных рубахах луговые мари применяли как правый ассиметричный, так и левый грудной разрезы, а восточные и горные мари располагали его по центру. Этот разрез, как правило, скреплялся завязками. В нагрудной вышивке мужской рубахи обычно размещался знак бороды, а на подоле рубахи в центральной части располагался обозначающий фаллос графический орнамент. Исследователи народной одежды склонны считать, что мужская марийская рубаха оказала влияние на мужской костюм русского населения Урало-Поволжья [5]. Штаны были с узким шагом (они также считаются наиболее архаичными). Зимние штаны изготавливались из домашнего полусукна. Пояс снабжался различными оберегами и имел функциональное назначение. К нему подвешивали ножны, кожаные мешочки для табака, огнива, трута, кошелёк для денег. В будние дни рубахи 

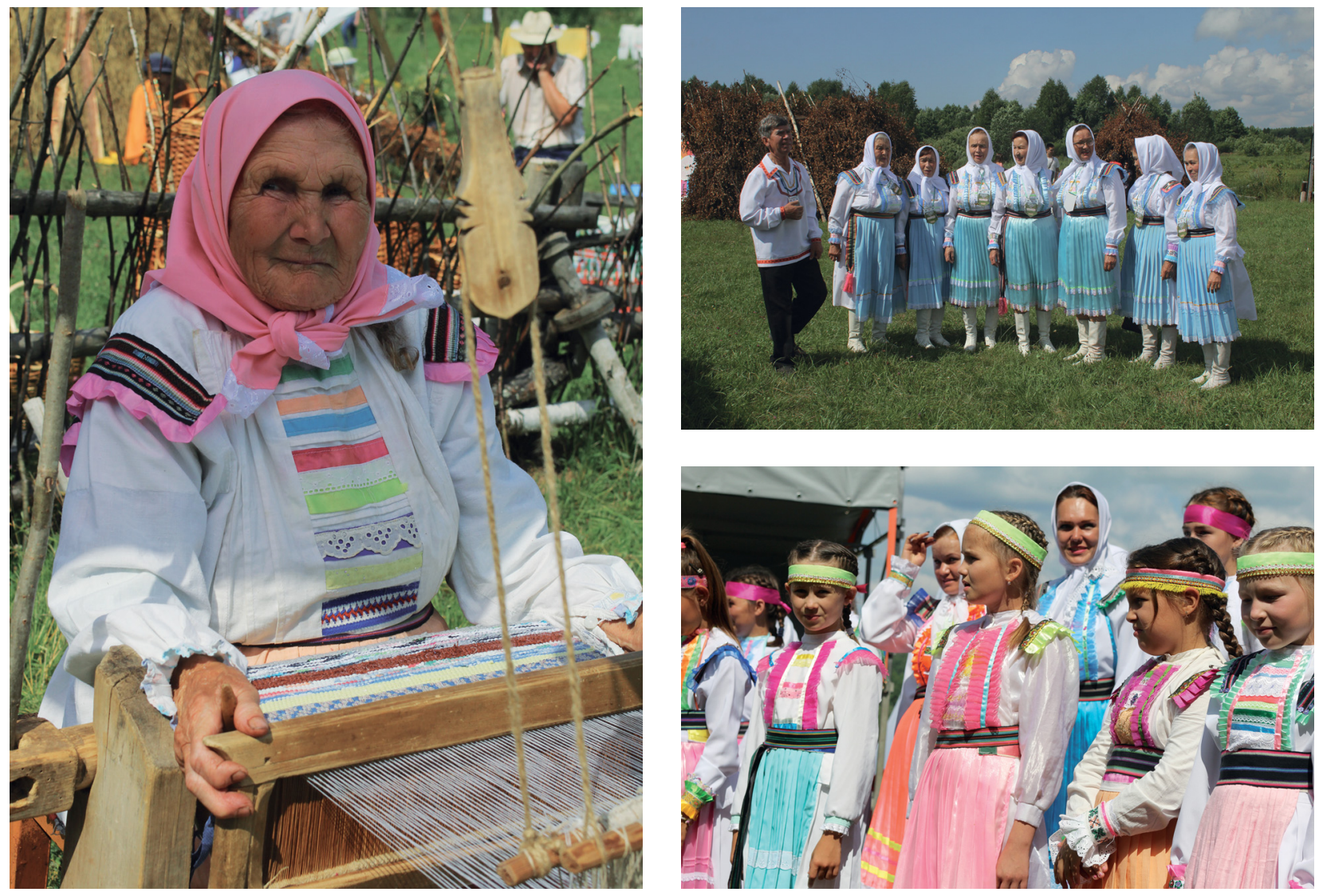

Фото 7. Современный костюм горных мари

опоясывались ремнём с медными и железными пряжками, а в праздники красным шерстяным поясом с кистями и ремешками, вырезанными из шкуры жертвенного животного. Пояса были кожаные, также тканые шерстяные, шёлковые и конопляные. Праздничные пояса богато декорировались бисером, серебряными монетами, вышивкой. Широкие домотканые кушаки использовались для опоясывания верхней одежды. Холщовые пояса в виде полотенца с вышитым или тканым узором надевались во время языческих молений, проводимых в священных рощах.

Важной частью традиционного мужского костюма являлись кафтаны - летние, демисезонные и зимние.

Круглые войлочные шляпы упш, терку́nш изготовляли в домашних условиях. Для праздничных головных уборов предназначалась белая шерсть, чёрная же использовалась для повседневных.
Округлой форме шляпы предшествовал головной убор из меха или кожи, а также берестяной конусообразный головной убор марийского жреца. Зимой мужчины надевали шапки с овчинным околышем и суконным верхом и шапки-ушанки.

Наряду с наиболее распространённой кожаной обувью (сапоги) носили валенки и лыковые лапти. Из кожи делали ремни и шили перчатки. Особым мастерством изготовления и высоким художественным вкусом выделяются декорированные металлическими бляшками кожаные кошельки.

Повседневной обувью мужчин были лапти, сплетённые из семи лык с оборами из этого же материала, при помощи которых лапти закреплялись на ноге. Марийские лапти сочетали прямое и косое плетение. Подошва у них была двойной. Их носили с онучами: летом - с холщовыми, а зимой - с суконными. В дождливую погоду на лапти надевали кожаные 


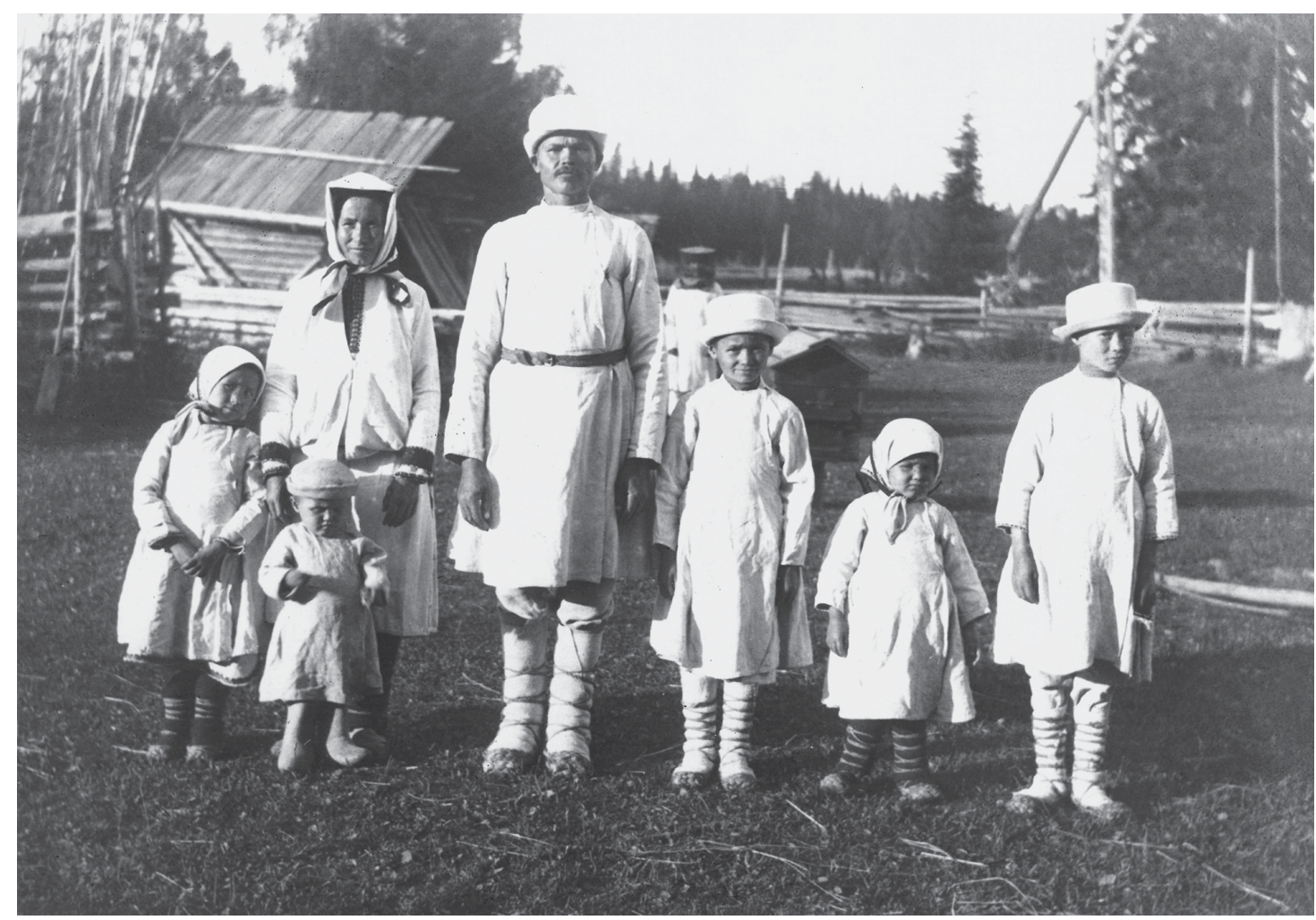

Фото 8. Представитель религиозной секты «Кугу сорта» ("Большая свеча») Е.Т. Киндулкин с семьёй. 1916 год.

Из фондов Национального музея Республики Марий Эл им. Т.Е. Евсеева

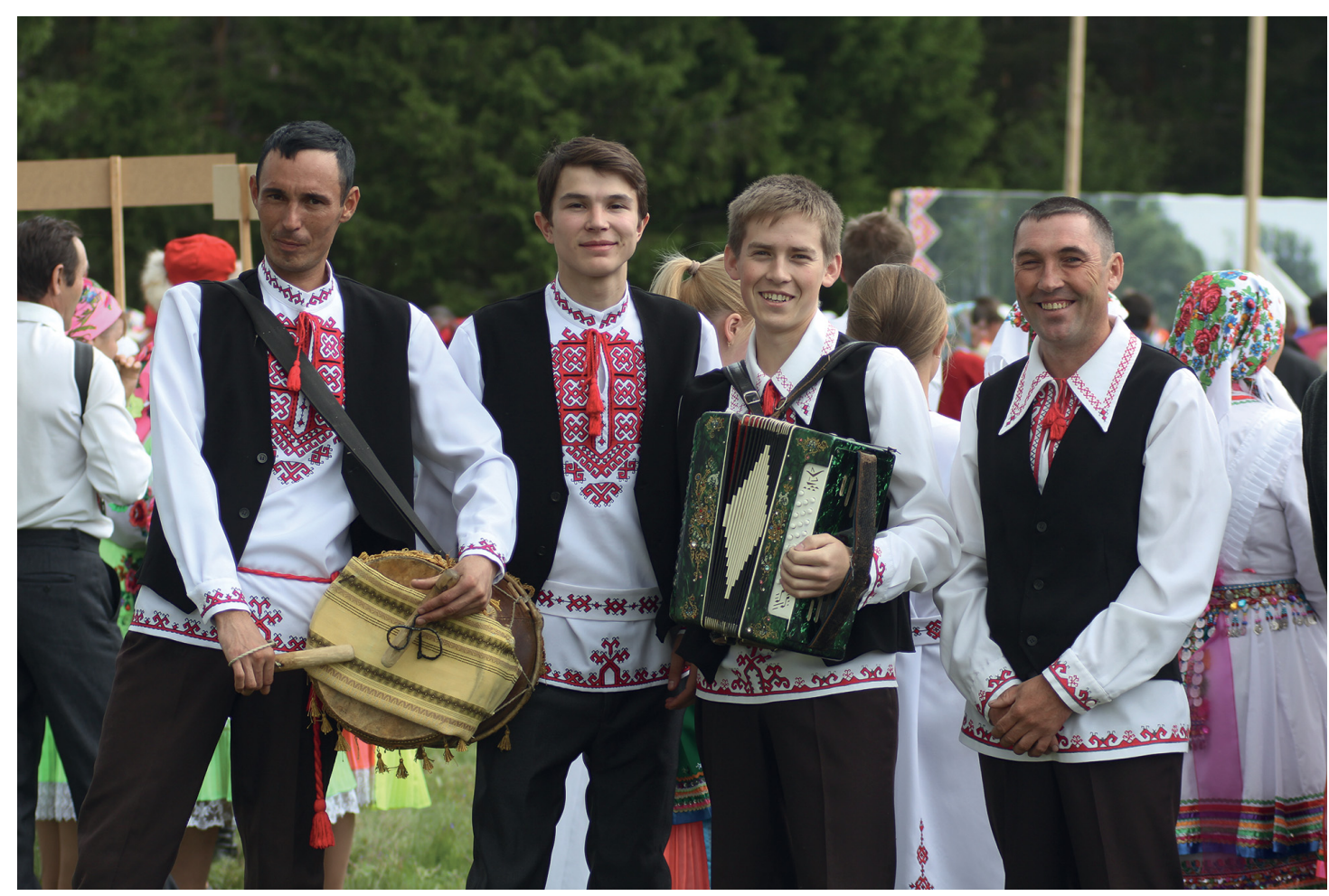

Фото 9. Современный марийский мужской костюм 
бахилы. Мужчины носили кожаные сапоги, восточные мари - сапоги-коты с суконными и войлочными голенищами. Они были восприняты от башкир. Кожаная обувь высоко ценилась. Наиболее модными считались сапоги со сборами в нижней части голенища. Зимой носили валенки. Среди состоятельных мари были популярны фабричные узорные валенки [7, с. 18-41].

Таким образом, приспособленный к условиям повседневного труда и быта народный костюм с традиционными фор- мами кроя был искусно декорирован металлическими украшениями и сочетал в себе богато орнаментированные традиции этнической культуры. И поскольку в настоящее время велика потребность современного общества в сохранении и трансляции традиционных образцов культуры, изучение семантической системы традиционного марийского народного костюма и его художественно-образная интерпретация представляет перспективную область для этнодизайна, истории искусства и культурологии.

\section{литеРАтУРА $\sim 0$}

1. Архипов Г.А. Марийский край в памятниках археологии. Йошкар-Ола: Марийск. кн. изд-во, 1976. 197 с.

2. Гаген-Торн Н.И. Женская одежда народов Поволжья (материалы к этногенезу). Чебоксары: Чувашгосиздат, 1960. 228 с.

3. Голубева Л.А. Зооморфные украшения финно-угров // Археология СССР. Свод археологических источников. Е 1-59. М., Наука, 1979. 176 с.

4. Дадаш С. Теория формального изобразительного языка тюркской миниатюры. Стамбул: Mega, 2006. 123 с.

5. Козлова К.И. Очерки этнической истории марийского народа. М.: Изд-во МГУ, 1978. 345 c.

6. рюкова Т.А. Материальная культура марийцев XIX века. Йошкар-Ола: Марийск. кн. изд-во, 1956. 160 с.

7. Кудрявцев В.Г. Художественная культура марийского народа. Народное творчество, деревянное зодчество, изобразительное искусство. Йошкар-Ола: Марийск. кн. изд-во, 2017. $256 \mathrm{c}$.

8. Молотова Т.Л. Марийский народный костюм. Йошкар-Ола: Марийск. кн. изд-во, 1992. 112 c.

9. Никитина Т.Б., Ефремова Д.Ю. Особенности погребений с орудиями литья на марийских могильниках IX-XII вв. // Финно-угроведение. 2011. № 2. С. 12-24.

10. Павлова А.Н. Костюм волжских финнов как этнокультурный феномен. Йошкар-Ола: Марийск. гос. ун-т, 2006. 200 с.

11. Павлова А.Н. Семантика традиционного марийского костюма и особенности её современного восприятия // Грамота, 2015. № 12 (62), часть 3. С. 123-125.

12. Сепеев Г.А. Восточные марийцы. Историко-этнографическое исследование материальной культуры (середина XIX - начало XX вв.). Йошкар-Ола: Марийск. кн. изд-во, 1975. 247 c.

Об авторе:

Кудрявцев Владимир Геннадьевич, доктор искусствоведения, профессор кафедры культуры и искусств, Марийский государственный университет (424000, г. Йошкар-Ола, Россия), ORCID: 0000-0002-1421-1664, vladku2004@mail.ru 


\section{U REFERENCES}

1. Arkhipov G.A. Mariyskiy kray v pamyatnikakh arkheologii [The Mari Country in Monuments of Archeology]. Yoshkar-Ola: Mari Book Publishing House, 1976. 197 p.

2. Gagen-Torn N.I. Zhenskaya odezhda narodov Povolzh'ya (materialy k etnogenezu) [HagenThorn N.I. Women's Clothing of the Peoples of the Volga Region (Materials for Ethnogenesis)]. Cheboksary: Chuvashgosizdat, 1960. 228 p.

3. Golubeva L.A. Zoomorfnye ukrasheniya finno-ugrov [Zoomorphic Adornments of the Finno-Ugric Peoples]. Arkheologiya SSSR. Svod arkheologicheskikh istochnikov. E 1-59 [Archeology of the USSR. The Sum of Archaeological Sources. E 1-59]. Moscow: Nauka, 1979. $176 \mathrm{p}$.

4. Dadash S. Teoriya formal'nogo izobrazitel'nogo yazyka tyurkskoy miniatyury [The Theory of Formal Pictorial Language of the Turkic Miniature]. Istanbul: Mega, 2006. 123 p.

5. Kozlova K.I. Ocherki etnicheskoy istorii mariyskogo naroda [Essays on the Ethnic History of the Mari People]. Moscow: Moscow State University Press, 1978. 345 p.

6. Kryukova T.A. Material'naya kul'tura mariytsev XIX veka [The Material Culture of the Mari of the 19th Century]. Yoshkar-Ola: Mari Book Publishing House, 1956. 160 p.

7. Kudryavtsev V.G. Khudozhestvennaya kul'tura mariyskogo naroda. Narodnoe tvorchestvo, derevyannoe zodchestvo, izobrazitel'noe iskusstvo [The Artistic Culture of the Mari People. Folk Art, Wooden Architecture, Fine Arts]. Yoshkar-Ola: Mari Book Publishing House, 2017. 256 p.

8. Molotova T.L. Mariyskiy narodnyy kostyum [The Mari Folk Costume]. Yoshkar-Ola: Mari Book Publishing House, 1992. 112 p.

9. Nikitina T.B., Efremova D.Yu. Osobennosti pogrebeniy s orudiyami lit'ya na mariyskikh mogil'nikakh IX-XII vv. [Features of Burials with Casting Tools at the Mari Burial Grounds from the 9th to the 12th Centuries]. Finno-ugrovedenie [Finno-Ugric Studies]. 2011. No. 2, pp. 12-24.

10. Pavlova A.N. Kostyum volzhskix finnov kak etnokul'turnyy fenomen [The Costume of the Volga Finns as an Ethnocultural Phenomenon]. Yoshkar-Ola: Mari State University, 2006. 200 p.

11. Pavlova A.N. Semantika traditsionnogo mariyskogo kostyuma i osobennosti ee sovremennogo vospriyatiya [The Semantics of the Traditional Mari Costume and the Peculiarities of its Modern Perception]. Gramota, 2015. No. 12 (62), part 3, pp. 123-125.

12. Sepeev G.A. Vostochnye mariytsy. Istoriko-etnograficheskoe issledovanie material'noy kul'tury (seredina XIX - nachalo XX vv.) [The Eastern Maris. Historical and Ethnographic Studies of Material Culture (From the Mid-19th to the Early 20th Centuries)]. Yoshkar-Ola: Mari Book Publishing House, 1975. 247 p.

About the author:

Vladimir G. Kudryavtsev, Dr.Sci. (Arts), Professor of the Department of Culture and Arts, Mari State University (424000, Yoshkar-Ola, Russia), ORCID: 0000-0002-1421-1664, vladku2004@mail.ru

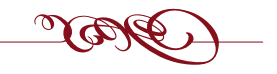

